\title{
Antenatal Detection of Hemoglobinopathies using Red Blood Cells Indices for Screening
}

\author{
${ }^{1}$ Sukanya Singh, ${ }^{2}$ Lalna R Takale, ${ }^{3}$ Mona Tilak
}

\begin{abstract}
Introduction: Hemoglobinopathies are a group of inherited disorders because of abnormalities in hemoglobin synthesis or structure. Thalassemia and sickle cell anemias are the most prevalent hemoglobinopathies and a national health burden. To reduce this burden, detecting them in the carrier stage is crucial. The health of pregnant women determines the future of the progeny. Hence identifying these disorders during the antenatal period is necessary to take the appropriate measures. Complete blood count (CBC) and peripheral smear are routinely done investigations during antenatal check up. Red blood cell (RBC) indices like mean corpuscular volume (MCV) and mean corpuscular hemoglobin $(\mathrm{MCH})$ can be used for initial screening, followed by electrophoresis for detecting these hemoglobinopathies.
\end{abstract}

Aim: To determine the prevalence of hemoglobinopathies during antenatal period using red blood cell indices for screening.

Materials and methodology: The study included 80 pregnant women whose $\mathrm{CBC}$ revealed $\mathrm{MCV} \leq 80 \mathrm{fL}, \mathrm{MCH} \leq 27$ pg and microcytic hypochromic picture on peripheral smear. Hemoglobin electrophoresis was done to detect hemoglobinopathies.

Results: Elevated $\mathrm{HbA} 2$ fraction $(>3.5 \%)$ was found in 5 $(6.25 \%)$ women suggestive of $\beta$-thalassemia trait. $\mathrm{HbA}$ and $\mathrm{HbS}$ bands were present in $3(3.75 \%)$ subjects suggestive of sickle cell trait.

Conclusion: Red blood cell (RBC) indices, $\mathrm{MCV}$ and $\mathrm{MCH}$, can be used for initial screening of hemoglobinopathies followed by more confirmatory methods (electrophoresis). Detection of these hemoglobin disorders in the carrier stage would thus be possible.

Clinical significance: Simple screening methods can reduce the incidence of the most prevalent hemoglobinopathies ( $\beta$-thalassemia trait and sickle cell trait/disease) during antenatal care.

Keywords: Antenatal, $\beta$-thalassemia trait, Red blood cell indices, Sickle cell disease/trait.

\footnotetext{
${ }^{1}$ Student, ${ }^{2}$ Associate Professor ${ }^{3}$ Professor and HOD

${ }^{1-3}$ Department of Biochemistry, Dr. D.Y. Patil Medical College,Hospital and Research Center, Pimpri, Pune, Dr. D.Y Patil Vidyapeeth, Pune, Maharashtra, India
}

Corresponding Author: Lalna R Takale, Associate Professor, Department of Biochemistry, Dr. D.Y. Patil Medical College, Hospital and Research Center, Pimpri, Pune, Dr. D.Y Patil Vidyapeeth, Pune, Maharashtra, India, Phone: 02025281032, e-mail: drlalna@yahoo.com
How to cite this article: Singh S, Takale LR, Tilak M. Antenatal Detection of Hemoglobinopathies using Red Blood Cells Indices for Screening. Indian J Med Biochem 2018;22(2):100-104.

\section{Source of support: Nil}

Conflict of interest: None

\section{INTRODUCTION}

Hemoglobinopathies are a group of inherited conditions characterized by abnormalities in synthesis or structure of hemoglobin $(\mathrm{Hb})$. World Health Organisation (WHO) estimates that $7 \%$ of the world population is a carrier of $\mathrm{Hb}$ disorders, leading to high morbidity and mortality. To reduce the burden of this highly prevalent monogenic disorders, detecting them in the carrier stage is crucial to prevent disease progression. ${ }^{1}$

In India, thalassemia and sickle cell anemia are the most prevalent hemoglobinopathies. The burden of thalassemia carriers in India is 3 to $4 \%$, and 8000 to 10,000 children are diagnosed with thalassemia major at birth. ${ }^{2}$ Average frequency of sickle cell disease is $4.3 \%$. It is prevalent in many central states of India like Gujrat, Maharashtra, Madhya Pradesh, etc., and in southern states of Telangana, Kerala. ${ }^{3}$

The health of pregnant women determines the future of the progeny. The concept of "fetal origin of adult disease" has gained immense importance in recent years. The effect of maternal hematological parameters on obstetric outcome has public health importance. These indicators are associated with infant health and survival and influences intrauterine development and health in later life. ${ }^{4}$ Investigations to determine the genetic burden of $\mathrm{Hb}$ disorders during antenatal care is thus the need of the hour.

The clinical presentation of hemoglobinopathies varies widely from being asymptomatic on one hand whereas, on the other hand, it can be a life-long condition requiring regular blood transfusions. ${ }^{5}$ Not only this, it needs to be distinguished from iron deficiency anemia.

In India, the prevalence of iron deficiency anemia is high in the general population. During pregnancy there is an additional requirement of iron, hence there is an increased likelihood of developing this nutritional deficiency. Though iron deficiency anemia (IDA) and hemoglobinopathies, especially beta thalassemia trait ( $\beta$-TT), may differ in their clinical manifestations they show some 
common diagnostic characteristics and create a dilemma. Microcytic hypochromic peripheral smear is a common finding in both these conditions. Differentiating them is crucial from a therapeutic aspect, as IDA would require iron supplementation whereas it is necessary to prevent thalassemia syndrome in thalassemia carriers. ${ }^{6-8}$

Complete blood count and peripheral smear examination are simple and routinely done investigations during antenatal care. This study aimed to assess the use of RBC indices for initial screening followed by electrophoresis to determine the occurrence of hemoglobinopathies during the an tenatal period.

\section{MATERIALS AND METHODOLOGY}

The study was carried out throughout 2 months from 1st August to 30th September 2016 at a tertiary care center.

\section{Selection of Subjects}

Pregnant women attending the obstetric outpatient department (OPD) for antenatal care who had either:

- History of unexplained anemia or

- The family history of anemia or hemoglobinopathy

\section{Inclusion Criteria}

Subjects between age 20 and 40 years with no known medical disorder, and irrespective of the trimester.

The study included 80 antenatal women with:

- Complete blood count (CBC) showing means corpuscular volume $(\mathrm{MCV}) \leq 80 \mathrm{fL}$, mean corpuscular hemoglobin $(\mathrm{MCH}) \leq 27 \mathrm{pg}$ and microcytic hypochromic picture on peripheral smear. ${ }^{9}$

\section{Exclusion Criteria}

Subjects already diagnosed to have hemoglobinopathy or have been screened previously.

- Subjects with iron deficiency anemia were also excluded.

- Institutional ethical committee clearance was obtained.

- Written informed consent was taken from the subjects. The following investigations were carried out:

- Complete blood count on sysmex automated hematology analyzer KX-21.

- Hemoglobin $(\mathrm{Hb})$ electrophoresis on semi-automated Helena SAS-MX.

\section{Sample Collection and Analysis}

The samples were collected in EDTA bulbs. They were then analyzed on sysmex automated hematology analyzer KX-21. The CBC report was studied and $\mathrm{RBC}$ indices were noted.
The samples with $\mathrm{MCV} \leq 80 \mathrm{fL}, \mathrm{MCH} \leq 27 \mathrm{pg}$ were further taken for electrophoresis.

Hemolysate was prepared and used for electrophoresis.

Hemoglobin electrophoresis was performed on semiautomated helena SAS-MX The normal $\mathrm{Hb}$ fractions in adults are adult $\mathrm{Hb}, \mathrm{HbA}$ composed of $\alpha 2 \beta 2$ globin chains (95 to $98 \%$ ), minor $\mathrm{Hb}, \mathrm{HbA} 2$ comprising of $\alpha 2 \delta 2$ globins ( 2 to $3 \%$ ), and fetal $\mathrm{Hb}, \mathrm{HbF}$ made of $\alpha 2 \gamma 2$ globins (up to $2 \%$ ).

A value of $\mathrm{HbA} 2>3.5 \%$ was taken as the cut-off for determining thalassemia trait. ${ }^{10,11}$

\section{RESULTS}

The results revealed that out of the 80 pregnant women whose RBC indices showed microcytosis (MCV $<80 \mathrm{fL}$, $\mathrm{MCH}<27 \mathrm{pg}),{ }^{5}(6.25 \%)$ women had elevated $\mathrm{HbA} 2$ fractions $(>3.5 \%)$ suggestive of $\beta$-thalassemia trait. Figure 1 shows hemoglobin electrophoresis with elevated $\mathrm{HbA} 2$ fraction. ${ }^{3}$ Total of $3.75 \%$ women had $\mathrm{HbA}$ and $\mathrm{HbS}$ band on electrophoresis indicative of sickle cell trait. Figure 2 shows the $\mathrm{HbA}$ and $\mathrm{HbS}$ band on electrophoresis of a woman with sickle cell trait.

Table 1 gives the hematological data expressed as a mean \pm standard deviation.

The mean age of women included in the study was $24 \pm 4$ years. The mean hemoglobin $(\mathrm{Hb})$ values were $9.08 \pm 1.7$. Out of the 80 pregnant women $7.5 \%$ had severe anemia $(\mathrm{Hb}<7 \mathrm{gm} / \mathrm{dL}), 53.75 \%$ moderate anemia ( $\mathrm{Hb} 7$ to $9.9 \mathrm{gm} / \mathrm{dL}$ ) whereas $22.5 \%$ had mild anemia (Hb10-10.9 $\mathrm{gm} / \mathrm{dL})$.

Table 2 shows the hematological data of women with $\beta$-thalassemia trait and sickle cell trait. The MCV, MCH values were higher in women with sickle cell trait as compared to the thalassemia trait, whereas the $\mathrm{Hb}$ and

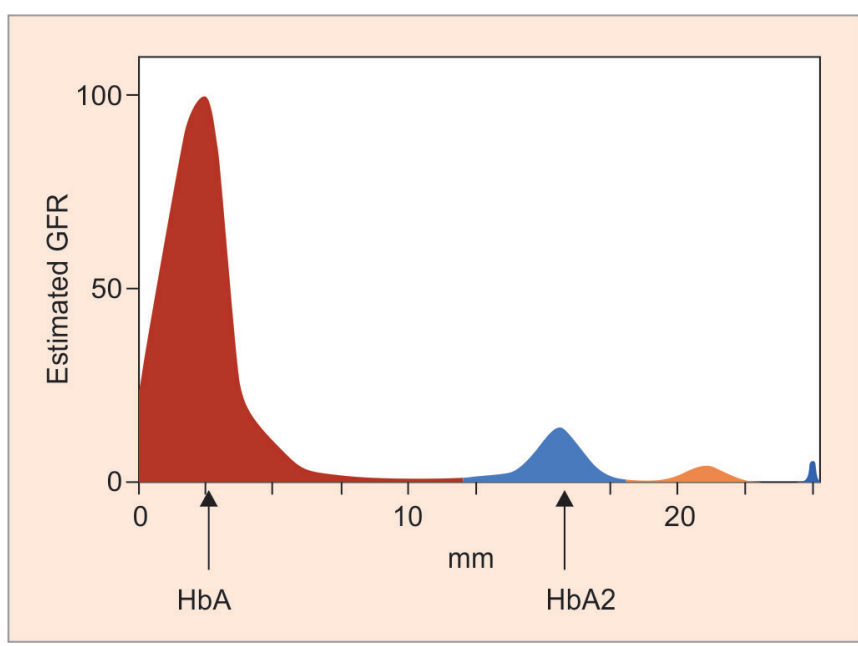

Fig. 1: Hemoglobin electrophoresis showing elevated $\mathrm{HbA} 2$ fraction indicative of $\beta$-thalassemia trait 
RBC were lower in sickle cell trait when compared with $\beta$-thalassemia trait.

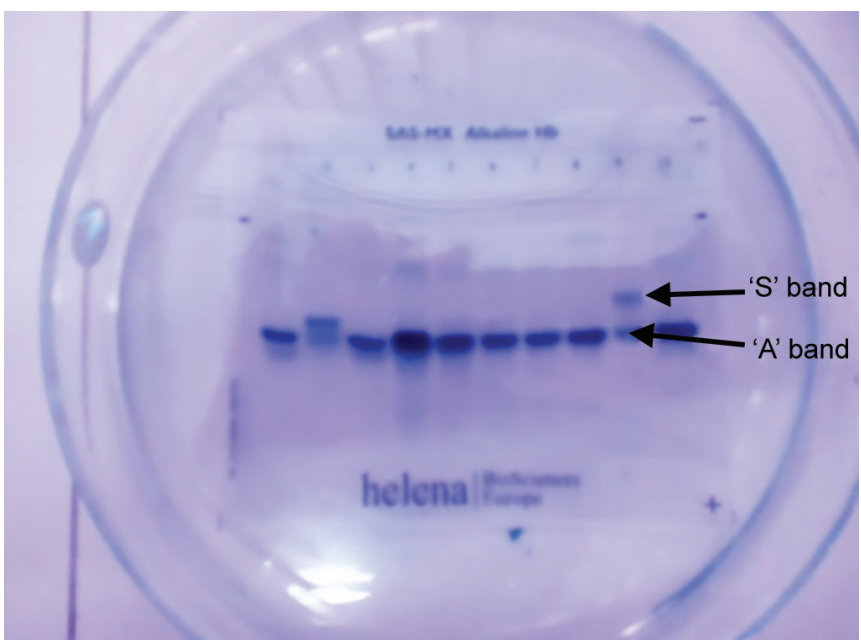

Fig. 2: Hemoglobin electrophoresis: Presence of 'A' and 'S' bands, suggestive of sickle cell trait

Table 1: Mean values and standard deviation of haematological data

\begin{tabular}{ll}
\hline Parameters & Mean $+/-S D$ \\
\hline $\mathrm{Hb}(\mathrm{gm} / \mathrm{dL})$ & $9.08+/-1.7$ \\
$\mathrm{MCV}(\mathrm{fL})$ & $69.23+/-7.55$ \\
$\mathrm{MCH}(\mathrm{pg})$ & $20.90+/-3.49$ \\
$\mathrm{RBC}\left(\right.$ millions $\left./ \mathrm{mm}^{3}\right)$ & $4.3+/-1.6$ \\
\hline
\end{tabular}

\section{DISCUSSION}

Hemoglobinopathies are autosomal recessive inherited disorders. Thalassemia is due to genetic defects affecting the production of specific globin chain of hemoglobin, $\alpha$ or $\beta$. In $\beta$-thalassemia, there is reduced production of $\beta$ globin chains which leads to decreased $\mathrm{HbA}(\alpha 2 \beta 2)$. This imbalance is compensated by increased production of $\delta$ and $\gamma$ chains, and hence there is an increase in $\mathrm{HbA} 2$ $\left(\alpha 2 \delta 2\right.$ ) fraction and $\mathrm{HbF}^{12}$

Sickle cell anemia occurs because of specific mutations in the $\beta$ globin gene resulting in the production of the structurally abnormal $\beta$ globin chain.

If one parent has a $\beta$-thalassemia trait and the other has normal $\mathrm{HbA}$, there is $50 \%$ (1 in 2 ) chance of having a child with $\beta$-thalassemia trait with each pregnancy. But if both parents have $\beta$-thalassemia trait, the chance of having a child with thalassemia major is $25 \%$ (1 in 4 ) and being a carrier is $50 \%$. Hence, screening of the spouse is also important to prevent the birth of homozygous thalassemia major child.

The pattern of inheritance for sickle cell anemia is as shown in Figure 3.

Thus, detecting sickle cell trait during the antenatal period would be helpful to make the woman and her

Table 2: Hematological data of women with $\beta$-thalassemia trait and sickle cell trait

\begin{tabular}{llllll}
\hline Hemoglobinopathy & No.of cases $(\%)$ & $H b(\mathrm{gm} / \mathrm{dL})$ & $M C V(f L)$ & $M C H(p g)$ & $R B C\left(\mathrm{millions}^{\mathrm{m}} \mathrm{mm} \mathrm{m}^{3}\right)$ \\
\hline B-thalassemia trait & $5(6.25 \%)$ & $8.8+/-3.6$ & $60.2+/-9.9$ & $17+/-1.5$ & $5+/-0.9$ \\
Sickle cell trait & $3(3.75 \%)$ & $7.8 \pm 4.4$ & $64.7 \pm 21$ & $19.6 \pm 8.8$ & $3.9 \pm 1$ \\
\hline
\end{tabular}

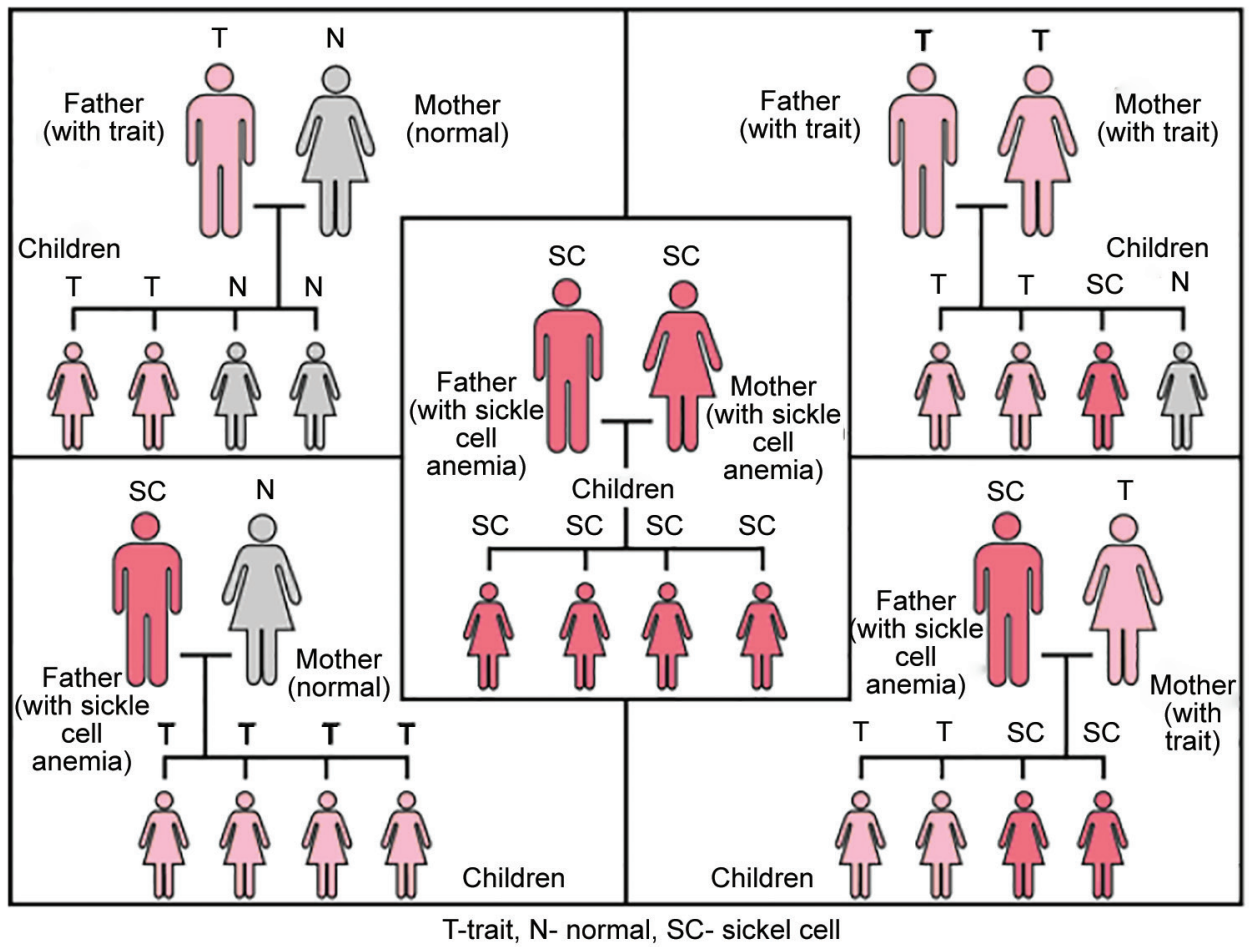

Fig. 3: Pattern of inheritance for sickle cell anemia 
family aware about the preventive measures and possible complications that would arise if the child is born with the trait or disease. ${ }^{13}$

This emphasizes the fact that detecting hemoglobinopathies during the carrier state is necessary. The screening can be best done in the premarital stage, but it may not be possible in all the communities and ethnic groups, so the ideal candidate for this would be pregnant women.

Simple hematological parameters like RBC indices can be used to detect the carrier state. ${ }^{14}$ A decrease in $\mathrm{MCV}<80 \mathrm{fL}$ and $\mathrm{MCH}<27 \mathrm{pg}$ indicates microcytosis and is suggestive of thalassemia trait. In sickle cell trait, the indices may be normal but the presence of sickle cell shaped RBCs on peripheral smear are highly suggestive. The confirmation of these traits has to be done by $\mathrm{Hb}$ electrophoresis or HPLC. Increase in $\mathrm{HbA} 2$ fraction $>3.5 \%$ is an important marker of heterozygous $\beta$-thalassemia trait which may be clinically silent. ${ }^{10,11}$

Our study has revealed that the prevalence of $\beta$-thalassemia trait is $6.25 \%$ and sickle cell trait is 3.75\%. Similar findings were reported in earlier studies by Datar et al., Balgir et al. and Philip et al. ${ }^{1,4,13}$

Hemoglobinopathies are known to be prevalent in certain communities and ethnic groups in India. Apart from these, social factors like consanguineous marriage or marriage within the community increase the genetic pool of mutations responsible for the disease within the community. Hence, the best strategy for diagnosis at the prenatal level is to encourage geographic profiling of mutation in the population..$^{5-17}$ Early marriages, low literacy rate and a general lack of awareness further adds to the ignorance for early detection of this highly prevalent disorder.

The carriers of hemoglobinopathies can be identified by screening. Population screening would be ideal provided adequate technical and financial resources are available. Premarital detection is another effective time for screening but again may not be acceptable across all the communities. Preconception screening can also prove to be effective and is easily acceptable in urban areas. But the antenatal period is the time when the family is receptive and concerned about the well-being of the newborn. Thus antenatal detection of hemoglobinopathies would be appropriate if done in the early gestational period. Prenatal diagnosis would be required if carrier stage is detected later during pregnancy and this would create additional emotional turmoil and stress. ${ }^{18}$

Furthermore, those who are diagnosed to have trait may be counselled and if needed advised DNA analysis. Cascade screening of other family members and relatives may also be carried out.
The population, in general, should be educated and made aware of these inherited disorders. ${ }^{2}$ To tackle this public health problem, several states have initiated control programs. This should be supported by national thalassemic/sickle cell control program for the better outcome. Another approach for early detection of hemoglobinopathies is to screen all cases of microcytic hypochromic anemia for abnormal $\mathrm{Hb}$ variants. ${ }^{19}$

\section{LIMITATIONS OF THE STUDY}

The study was limited by the sample size and technical method used. High-performance liquid chromatography (HPLC) is a better method for quantitation of $\mathrm{HbA} 2$ levels as well as for detection of other $\mathrm{Hb}$ variants. Molecular studies by DNA analysis for detecting the exact mutation would be ideal for confirming the cases with $\beta$-thalassemia trait and for diagnosis of $\alpha$-thalassemia.

\section{CONCLUSIONS}

Hemoglobinopathies are a group of genetic disorders posing a national health burden. There is in general lack of awareness among patients about this potentially preventable inherited disorder. Use of simple, cost-effective screening methods at the antenatal care center may prove to be helpful to diagnose these disorders. Screening for these disorders during the first trimester of antenatal care is possible using simple hematological parameters. The strategy for screening is microcytic hypochromic with reduced MCV $(<80 \mathrm{fL})$ and $\mathrm{MCH}(<27 \mathrm{pg})$ followed by electrophoresis. $\mathrm{HbA} 2$ fraction $>3.5 \%$ on electrophoresis is an important marker for diagnosing $\beta$ thalassemia carriers and presence of $\mathrm{HbA}$ and $\mathrm{HbS}$ suggest sickle cell trait/disease. This would thus help to prevent and control the birth of child with thalassemia or sickle cell disease.

\section{REFERENCES}

1. Datar S, Poflee S, Shrikhande A. Premarital screening of college students for carrier detection in thalassemia and sickle cell disease: Need of the hour. International Journal of Medical Science And Public Health, 2015;4(3): 420-423.

2. Mendiratta SL, Mittal M, Naaz F, Singh S, Anand S. Role of thalassemia screening in prevention and control of thalassemia - a 5 year experience. Int J Reprod Contracept Obstet Gynecol 2016;5:3107-11.

3. Keshav Pagrut,Pratik Chide. Screening for the sickle cell gene in Yavatmal district, Maharashtra, India: An approach to a major health problem. International Journal of Biomedical and Advanced Research 2017; 8 (02):50-53.

4. Balgir RS. A cross-sectional study of haemoglobin disorders in pregnant women attending to urban hospitals in eastern coast of Odisha, India. Online Journal of Health and Allied Sciences, Vol.12, Issue 4, Oct-Dec 2013. 
5. Jain BB, Roy RN, Ghosh S, Ghosh T, Banerjee U, Bhattacharya SK. Screening for thalassemia and other hemoglobinopathies in a tertiary care hospital of West Bengal: Implications for population screening. Indian J Public Health 2012; 56: 297-300.

6. Hoffmann JJML, Urrechaga E, Aguirre U. Discriminant indices for distinguishing thalassemia and iron deficiency in patients with microcytic anemia: a meta-analysis. Clinical Chemistry and Laboratory Medicine (CCLM) [Internet]. Walter de Gruyter $\mathrm{GmbH} ; 2015$ Jan 1;53(12).

7. Jameel T, Baig $\mathrm{M}$ et al. Differentiation of beta thalassemia trait from iron deficiency anemia by haematological indices. Pakistan Journal of Medical Sciences 2017;33(3):665-669.

8. Vehapoglu A, Ozgurhan G, Demir AD, Uzuner S, Nursoy MA, Turkmen S, et al. Hematological Indices for Differential Diagnosis of Beta Thalassemia Trait and Iron Deficiency Anemia. Anemia [Internet]. Hindawi Limited; 2014;2014:1-7.

9. Moafi A, Valian S, Nikyar Z, Zeinalian M, Momenzadeh M, Rahgozar S. Prevalence of minor -thalassemia based on RBC indices among final suspected individuals in premarital screening program referred to Genetic Laboratories. International Journal of Hematology Oncology and Stem cell research 2010 Jan;4(1):23-27.

10. Ou Z, Li Q, Liu W, Sun X. Elevated Hemoglobin A2 as a Marker for -Thalassemia Trait in Pregnant Women. The Tohoku Journal of Experimental Medicine [Internet]. Tohoku University Medical Press; 2011;223(3):223-226.

11. Baxi A, Manila K, Kadhi P, Heena B. Carrier Screening for $\beta$ Thalassemia in Pregnant Indian Women: Experience at a Single Center in Madhya Pradesh. Indian Journal of Hematology \& Blood Transfusion. 2013;29(2):71-74. doi:10.1007/ s12288-012-0165-8.

12. Leung, TN, Lau TK, Chung TKH. Thalassaemia screening in pregnancy. Curr Opin Obstet Gynecol 2005;17:129-34.
13. Philip J, Sarkar RS, Kushwaha N. Microcytic hypochromic anemia: Should high performance liquid chromatography be used routinely for screening anemic and antenatal patients? Indian J Pathol Microbiol 2013; 56:109-13.

14. Tangvarasittichai O, Poonanan N, Tangvarasittichai S. Using Red Cell Indices and Reticulocyte Parameters for Carrier Screening of Various Thalassemia Syndromes. Indian Journal of Clinical Biochemistry [Internet]. Springer Nature; 2016 May 9;32(1):61-67.

15. Bhukhanvala DS, Sorathiya SM, Shah AP, Patel AG, Gupte SC. Prevalence and hematological profile of $\beta$-thalassemia and sickle cell anemia in four communities of Surat city. Indian Journal of Human Genetics. 2012;18(2):167-171.

16. Mohanty D, Colah RB, Gorakshakar AC, et al. Prevalence of $\beta$-thalassemia and other haemoglobinopathies in six cities in India: a multicentre study. Journal of Community Genetics. 2013;4(1):33-42.

17. Kumar R, Arya V, Agarwal S. Profiling Thalassemia Mutations in Consanguinity and Nonconsanguinity for Prenatal Screening and Awareness Programme. Advances in Hematology [Internet]. Hindawi Limited; 2015;2015:1-5.

18. Galanello R. Screening and Diagnosis for Haemoglobin Disorders. In: Angastiniotis M, Eleftheriou A, Galanello Ret al., authors; Old J, editor. Prevention of Thalassaemias and Other Haemoglobin Disorders: Volume 1: Principles [Internet]. 2nd edition. Nicosia, Cyprus: Thalassaemia International Federation; 2013. Chapter 4.

19. Bhalodia JN, Oza HV, Modi PJ, Shah AM, Patel KA, Patel HB. Study of Hemoglobinopathies in Patients of Anemia using High Performance Liquid Chromatography (HPLC) in Western India. Natl J Community Med. 2015;6(1): 35-40.on electrophoresis indicative of sickle cell trait. Figure 2 shows the $\mathrm{HbA}$ and $\mathrm{HbS}$ band on electrophoresis of a woman with sickle cell trait. 